\section{Impact of climate change on the heavy rainfall events during June to September over Kerala (1901-2019)}

\author{
Divya E. Surendran*, Latha Sridhar, \\ Aradhana Kumari, O. P. Sreejith and D. S. Pai \\ Climate Research and Services, India Meteorological Department, \\ Pune 411 005, India
}

\begin{abstract}
Heavy rainfall ( $\geq 100 \mathrm{~mm}$ or $\mathrm{HR})$ events and moderate rainfall ( $\geq 5 \mathrm{~mm}$ to $100 \mathrm{~mm}$ or MR) events over Kerala for June-September were analysed statistically to understand the influence of climate change in MR and HR events for the period 1901-2019 and its two different parts; 1901-1970 and 1971-2019. Most parts of coastal Kerala receive more than $50 \mathrm{HR}$ events/season except the southernmost parts which receive $40-50$ HR events/season. Significant negative trend was observed for MR $(99 \%)$ and HR $(95 \%)$ events for the entire period of 1901-2019. The total seasonal rainfall averaged over Kerala also showed significant negative trend during the entire period of 1901-2019. In dekad (10 days period) wise trend analysis for MR events during July and August, third dekad of July (21-31 July) showed significant negative trend for the entire period (99\%), second dekad of August (11-20 August) showed significant negative trend $(95 \%)$ for the second part of the data period. In case of $H R$ events, first and third dekads of July (1-10 July; 21-31 July) showed significant negative trends $(95 \%$ and $\mathbf{9 9 . 9 \%}$ respectively) for the entire data period. The third dekad of July (21-31 July) showed significant negative trend $(95 \%)$ for the first part of the data period (1901-1970) while the third dekad of July (21-31 July) showed significant negative trend $(95 \%)$ for second part (1970-2019). First dekad of August (1-10 August) showed significant increasing trend $(95 \%)$ for the second part of the data period exhibiting its peak in 2019 with 127 HR events. Both MR and HR events frequency during the entire data period was seen to be significantly decreasing $(99 \%$ and $95 \%)$ over the entire Kerala. HR events frequency over few grids of eastern part of the state showed significant increase in the second part of the data period (1971-2019), where Kerala recently experienced exceptionally heavy rainfall spells of shorter durations and landslides.
\end{abstract}

Keywords: Climate change, disaster potentials, gridwise trend analysis, heavy and moderate rainfall.

INTENSITY and frequency of extreme rainfall events and associated natural calamities are increasing every year ${ }^{1-3}$. Under the warming climate, these extreme events have major impacts on the society, economy and environment. Kerala, a maritime state of peninsular India, receives abundant rainfall. The average annual rainfall over Kerala

\footnotetext{
*For correspondence. (e-mail: divya.surendran@imd.gov.in)
}

is about three times the national average. Monsoon is the most important phenomenon controlling the regional climate of the state, mostly contributed by two seasons of rainfall, viz., the southwest (SW) monsoon (JuneSeptember) and the northeast (NE) monsoon (OctoberDecember). Kerala exhibits spatio-temporal variations in rainfall. The analysis of rainfall data of the last century indicates a significantly decreasing trend in the annual as well as SW monsoon rainfall ${ }^{4-9}$. Although rainfall in Kerala shows a decreasing trend in the SW monsoon season $^{8}$, two recent years (2018 and 2019) have exhibited exceptionally heavy rainfall spells (more than the annual average in many stations) of shorter duration (about 10 days) during July and August, causing damage to life and property. These extreme events are likely to be driven by anomalous atmospheric conditions due to climate variability and climate change. Hence, it would be of interest to study the dekad (10 days period)-wise long-term variation and trends in moderate rainfall (MR) and heavy rainfall (HR) events over Kerala during July and August in the present climate change scenario. For this, we divided the entire study period into two parts - the first part before the beginning of the warming era (1901-1970) and the second part from the beginning of warming era (1971-2019). A study had observed significant negative trend (at 95\%) in the MR events and significant positive trends (at 99\%) in the HR events over the west coast of India (extending from Konkan and Goa to the southern tip of Kerala $)^{10}$. In view of these observations, the objective of the present study was to analyse several climatological and variability features of daily rainfall events over Kerala, including long-term trends of MR and HR events for the period 1901-2019 and its two parts. The dekad-wise long-term variation and trends in MR and HR events over the state during July and August were also analysed.

For this study, the India Meteorological Department's (IMD's) daily gridded rainfall dataset of high spatial resolution $\left(0.25^{\circ} \times 0.25^{\circ}\right)$ covering a period of 119 years (1901-2019) over India was used ${ }^{11}$. This dataset was developed using daily rainfall data from all the rain-gauge stations over the country for the period 1901-2019 available in the archive of the National Data Centre, IMD, Pune. The daily rainfall records from 6955 rain-gauge stations in India with varying availability periods were used. This is the highest number of stations used by any study so far for preparing grid-point rainfall data over the entire country. Though the spatial density of station points was not uniform throughout the country, there were a good number of stations representing Kerala. Variability and trend analyses of MR and HR events were also carried out for the state during the SW monsoon season for the entire data period and its two parts. From the daily gridded rainfall data, seasonal mean and median, standard deviation (SD) and coefficient of variation (CV) were computed for the monsoon season (June-September). 
Dekad-wise analysis was carried out for July and August to examine the trend of MR and HR events. Trend analysis was carried out for June-July-August-September (JJAS) as well as dekad-wise (July and August) for the MR and HR rainfall events.

The spatial domain of Kerala encloses 75 grids, of which MR and HR events were experienced by 41 and 1 grid per day respectively. Most parts of coastal Kerala (about $55 \%$ of 75 grids) experienced more than $50 \mathrm{HR}$ events/season except the southernmost parts with 40-50 such events/season (Figure 1). The grid-wise trend analysis of frequency of the MR events revealed that out of 75 grids, $13.3 \%$ (64\%) showed significantly positive (negative) trends for the entire data period, $42.66 \%$ (37.35\%) showed significantly positive (negative) trends during the first part and $64 \%(21.33 \%)$ showed significantly positive (negative) trends during the second part (Table 1 and Figure $2 a$ ). The frequency of MR events over the northern and central parts of the state was seen to be significantly increasing during both the first and second parts of the period, while significantly decreasing for the entire period (1901-2019). It was also observed that the number of grids showing significant increase in the MR events over northern and central Kerala had increased in the last 49 years, whereas the number of grids showing significant decrease in these events over southeastern part of the state remained almost the same. For the HR events $9.33 \%$ (25.3\%) showed significantly positive (negative) trends for the entire data period; $17.34 \%$ (45.33\%) showed significantly positive (negative) trends during the first part, and $21.33 \%(41.34 \%)$ showed significantly positive

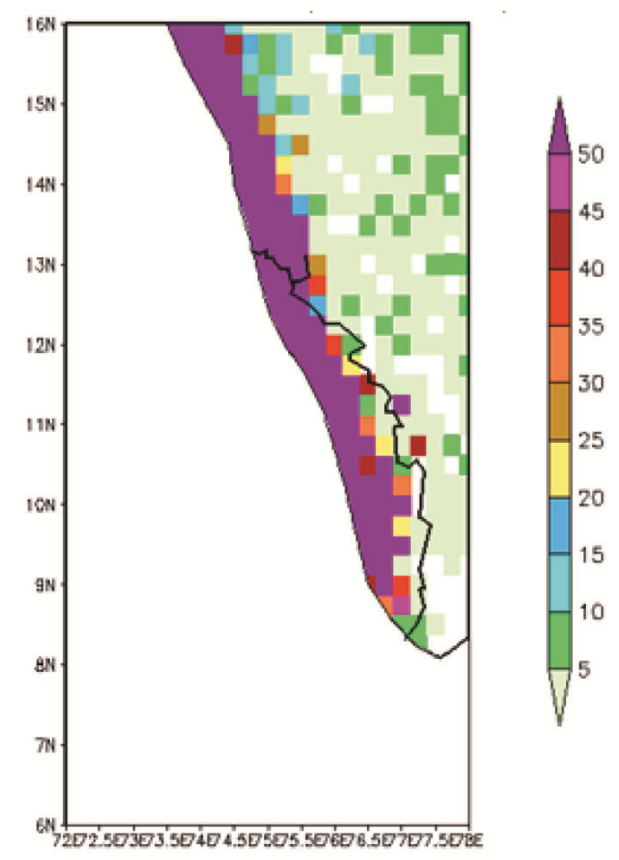

Figure 1. Number of heavy rainfall (HR) events over Kerala, India for June-July-August-September during the period 1901-2019. (negative) trends during the second part (Table 1 and Figure $2 b$ ). The frequency of HR events over some parts of northern Kerala was seen to significantly decrease in all the three time periods, while few grids over eastern Kerala showed significant increase in the second part of the data period.

The mean seasonal cycle in the number of MR events over Kerala showed an increase from about 32-44 events/day in the first week of June to about 50-52 events/day in the last week of June (Figure 3). The number of MR events remained slightly above 50 events/day till the last week of July. Thereafter, it showed a progressive decrease to about 25-30 events/day towards the end of the season with a slight increase of about 40-45 events/day during the third week of August. Thus, about 41 MR events occurred every day throughout the season. The mean seasonal cycle of the HR events over Kerala showed a progressive increase in the frequency of these events during June, peak in July and progressive decrease in August and minimum in September (Figure 3). During July, 1-3 HR events/day occurred over Kerala. Relatively fewer HR events occurred during September. Table 2 shows various statistics, including trends of areaweighted rainfall and grid-point MR and HR events during the SW monsoon season over Kerala. In order to examine the shift in rainfall characteristics, if any, between the two parts (1901-1970 and 1971-2019) of the data period, the statistics was also computed for each of these two periods (Table 2). Significant negative (99\%), long-term, linear trend was observed in the area-weighted rainfall season during the entire data period; however the trends were insignificantly negative during the two subperiods.

Figure $4 a$ and $b$ shows the year-to-year variation of the MR and HR events. It can be seen from the figure that there is not much year-to-year variation in the MR events, ranging from 6421 (1933) to 3688 (1918). In the present decade, 2018 and 2019 were among the top three years exhibiting maximum number of MR events; the highest number of MR events in the present decade was seen in 2013. With regard the HR events, the year 1924 (2012) exhibited the highest (lowest) number of such events, viz. 438 (10). During the present decade, 2019 exhibited the highest number (195) of HR events. It may also be mentioned that the area-weighted rainfall and CR (combined MR and HR) events of each of these three regions showed strong correlations. The $\mathrm{CC}$ between area weighted rainfall and the number of $\mathrm{CR}$ events during the data period 1901-2019 for Kerala was 0.85 (not shown in the table). It has been observed that, over Kerala, about $96.6 \%$ of rainfall events (rainfall $>0 \mathrm{~mm}$ ) were CR events with HR events contributing about $0.7 \%$. Thus most of the CR events were MR events (98\%) and HR events were significantly less compared to MR events. The mean and standard deviation of the area-weighted rainfall over Kerala for the monsoon season during the entire data 

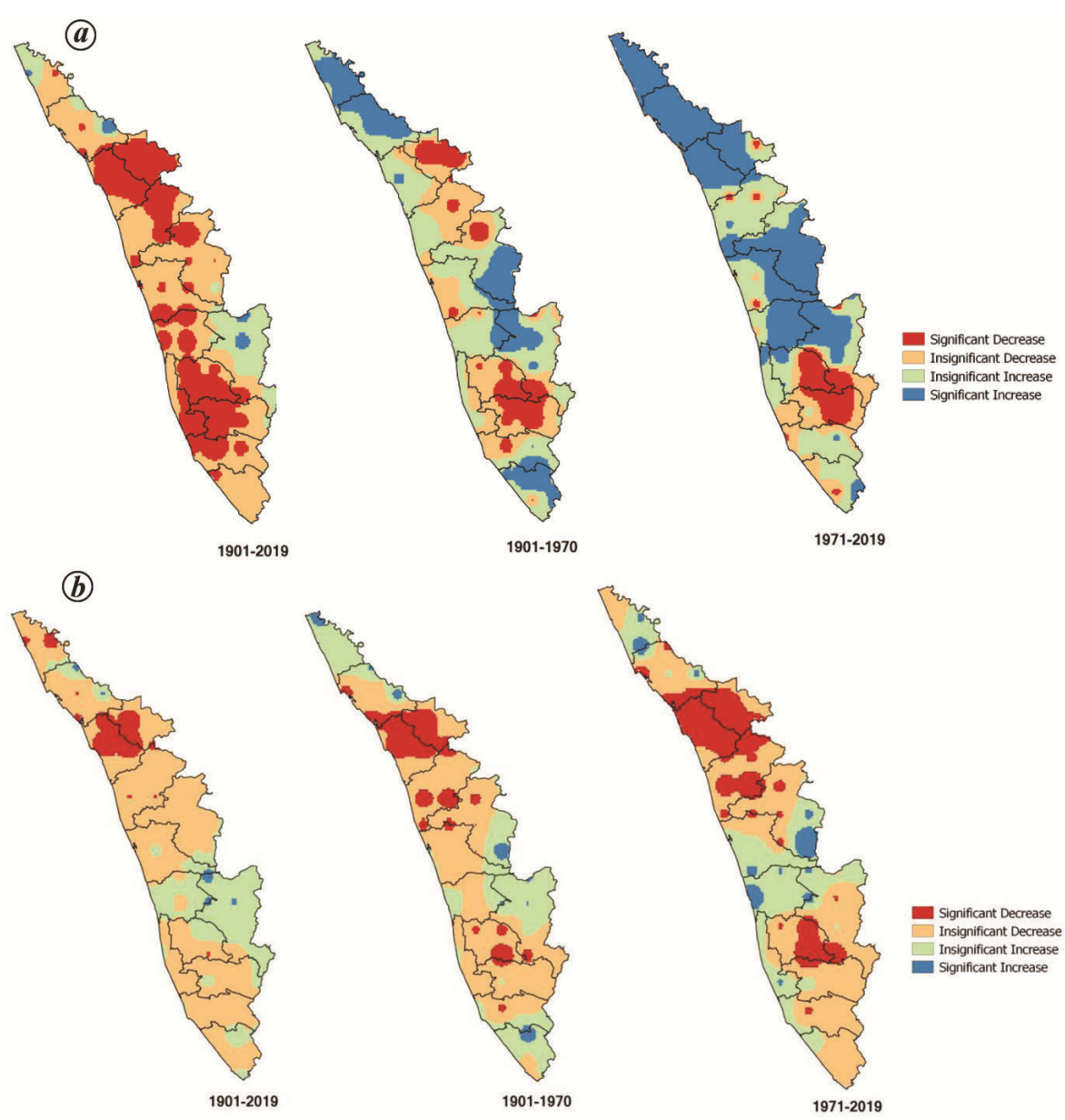

Figure 2. Grid-wise trend analysis of intensity of (a) moderate rainfall (MR) events and (b) HR events over Kerala.

Table 1. Percentage of grids showing trends in intensity of moderate rainfall (MR) and heavy rainfall (HR) events

\begin{tabular}{lcccccccc}
\hline & \multicolumn{3}{c}{ MR events intensity } & & \multicolumn{3}{c}{ HR events intensity } \\
\cline { 2 - 3 } \cline { 7 - 8 } Criteria & $1901-2019$ & $1901-1970$ & $1971-2019$ & & $1901-2019$ & $1901-1970$ & $1971-2019$ \\
\hline Significantly positive & 13.33 & 42.66 & 64 & & 9.33 & 17.34 & 21.33 \\
Positive but insignificant & 16.0 & 10.33 & 6.67 & & 38.66 & 24 & 24 \\
Significantly negative & 64.0 & 37.35 & 21.33 & & 25.33 & 45.33 & 41.34 \\
Negative but insignificant & 6.67 & 9.66 & 8.0 & & 26.66 & 13.33 & 13.33 \\
\hline
\end{tabular}

period of 1901-2019 were 16.1 and $3.15 \mathrm{~mm} /$ day respectively (Table 2), i.e. CV of $19.56 \%$.

Figure $5 a$ and $b$ shows the interannual variation of category-wise number of MR and HR events over Kerala for the entire data period with trend lines fitted for various data periods. As seen in Table 2 and Figure 5, during the total data period, significant negative trends were observed in the MR as well as HR events (at $99 \%$ and $95 \%$ respectively). Pai et al. ${ }^{10}$ observed significant negative trend (at 95\%) in the MR events and significant positive trends (at 99\%) in the HR events over the west coast of India (extending from Konkan and Goa to the southern tip of Kerala). Hence the significant positive trend over the west coast for the frequency of HR events can be attributed to the contribution of such events in Konkan and Goa region ${ }^{10}$. Among the sub-period trends, statistically insignificant positive (negative) trends were observed in the frequency of MR (HR) events during the first part. The trends during the second part were negative for both MR and HR events, though they were statistically insignificant.

Although the MR and HR events showed decreasing trends during the entire data period and its two parts, few years exhibited exceptionally heavy rainfall spells of shorter duration (about 10 days) during July and August, causing damage to life and property. In order to understand the trends of MR and HR events in shorter duration during these two months, dekad-wise trend analysis was 
Table 2. Statistical properties and trends of area weighted rainfall and grid point MR and HR events during the southwest monsoon season over Kerala

\begin{tabular}{|c|c|c|c|c|}
\hline & Rainfall categories & $1901-2019$ & $1901-1970$ & $1971-2019$ \\
\hline Mean (mm/day) & Area-averaged rainfall $(>0 \mathrm{~mm})$ & 16.1 & 16.84 & 15.06 \\
\hline Standard deviation (mm/day) & Area-averaged rainfall $(>0 \mathrm{~mm})$ & 3.15 & 3.09 & 2.97 \\
\hline Trend (mm/day) & Area-averaged rainfall ( $>0 \mathrm{~mm})$ & $-3.05 * *$ & -0.60 & -3.90 \\
\hline \multirow[t]{2}{*}{ Mean (grid point events per season) } & MR & 5020 & 5187 & 4781 \\
\hline & HR & 108 & 116 & 97 \\
\hline Standard deviation (grid point events per season) & HR & 60 & 65 & 51 \\
\hline \multirow[t]{2}{*}{ Median (grid point events per season) } & MR & 5051 & 5180 & 4782 \\
\hline & HR & 97 & 102 & 88 \\
\hline \multirow[t]{2}{*}{ Trend (grid point events per season) } & MR & $-4.7 * * *$ & 2.39 & -4.26 \\
\hline & HR & $-0.32 *$ & -0.31 & -0.30 \\
\hline
\end{tabular}

$*, * *$ and $* * *$ represent categories that are significant at $95 \%, 99 \%$ and $99.9 \%$ respectively.

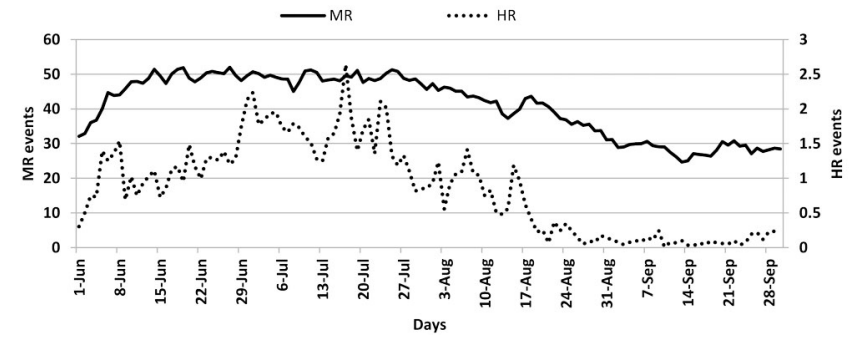

Figure 3. Mean seasonal cycle of daily mean number of MR and HR events over Kerala.
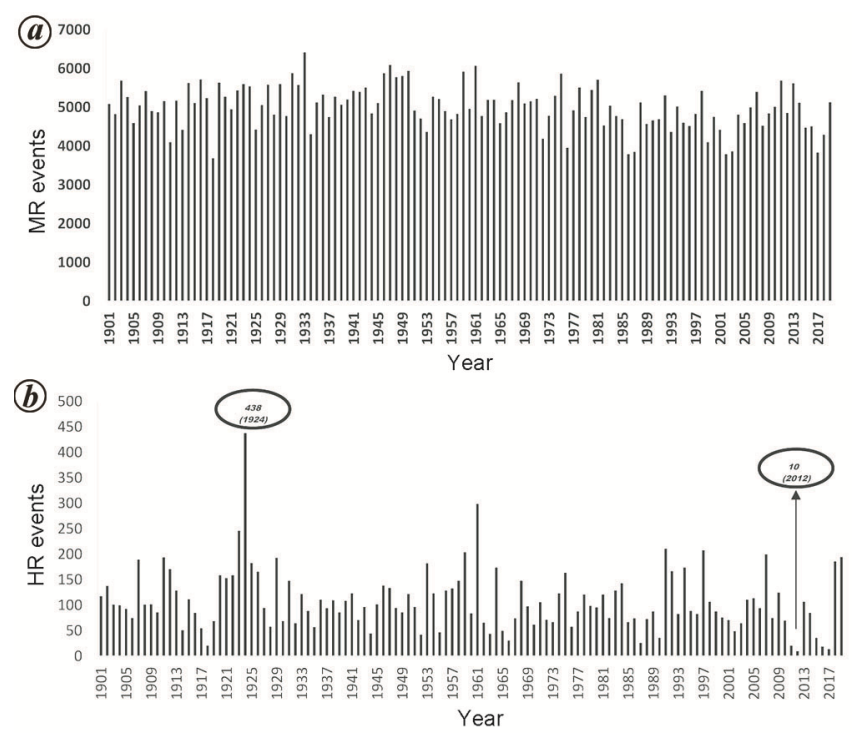

Figure 4. Year to year variation of (a) MR events and (b) HR events over Kerala.

carried out. For the MR events during July and August, all the dekads showed negative trends for the entire data period in which the third dekad of July (21-31) showed significance of 95\% (Table 3 and Figure 6). Except the third dekads of July and August, all dekads showed insignificant positive trends for the first part of the data
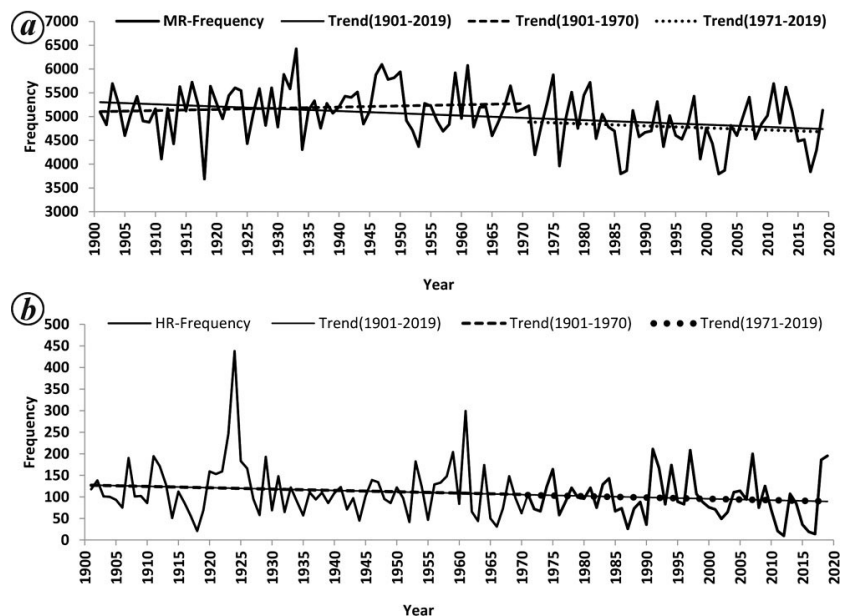

Figure 5. Interannual variation of category-wise number of (a) MR events and (b) HR events over Kerala.

period, whereas these two dekads showed insignificant negative trends. For the second part of the data period, all dekads of July and August showed negative trends in which the second dekad of August (11-20) was statistically significant $(95 \%)$. In case of the HR events, the first and third dekads of July (1-10 and 21-31) showed significant negative trends (95\% and 99\% respectively) for the entire data period (Table 3 and Figure 7). The second dekad of July showed statistically insignificant negative trend, though the trends for all the dekads of August were positive and statistically insignificant. During the first part of the data period (1901-1970), the third dekad of July showed significant negative trend (99\%). All the remaining dekads (except the second dekad of July), showed insignificant positive trends, while the second dekad showed insignificant negative trend for the period 1901-1970. The first and third dekads of July (1-10 and 21-31) showed negative trends for the second part (1971-2019) of the data period in which the third dekad (21-31) was statistically significant (95\%). In the remaining four dekads, the first dekad of August (1-10) showed 
RESEARCH COMMUNICATIONS

Table 3. Dekad-wise trend significance of MR and HR events over Kerala

\begin{tabular}{|c|c|c|c|c|c|c|}
\hline \multirow[b]{2}{*}{ Dekad } & \multicolumn{3}{|c|}{ MR events frequency } & \multicolumn{3}{|c|}{ HR events frequency } \\
\hline & 1901-2019 & $1901-1970$ & 1971-2019 & 1901-2019 & $1901-1970$ & 1971-2019 \\
\hline 1-10 July & -0.68 & 0.46 & -0.77 & $-0.14^{*}$ & 0.22 & -0.19 \\
\hline 11-20 July & -0.28 & 0.36 & -0.34 & -0.07 & -0.08 & 0.01 \\
\hline 21-31 July & $-0.94 * *$ & -0.38 & -0.49 & $-0.15 * *$ & $-0.23 * *$ & $-0.38^{*}$ \\
\hline 1-10 August & -0.40 & 0.73 & -0.10 & 0.04 & 0.05 & $0.46^{*}$ \\
\hline 11-20 August & -0.03 & 1.06 & $-2.68^{*}$ & 0.03 & 0.02 & 0.09 \\
\hline 21-31 August & -0.55 & -0.18 & -0.63 & 0.01 & 0.09 & 0.03 \\
\hline
\end{tabular}

$*, * *$ and $* * *$ represent categories that are significant at $95 \%, 99 \%$ and $99.9 \%$ respectively.
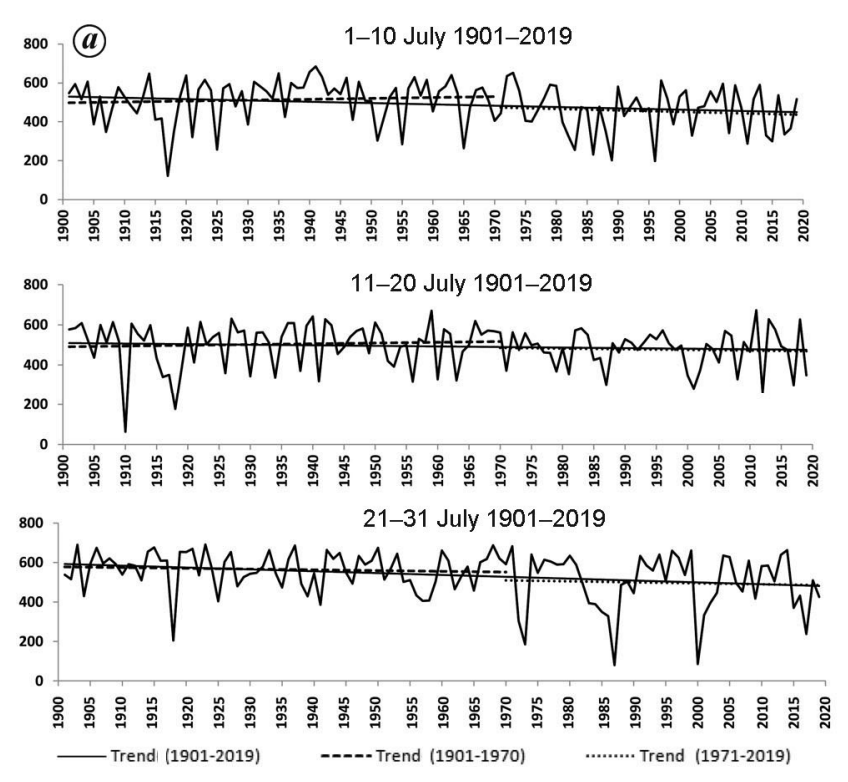
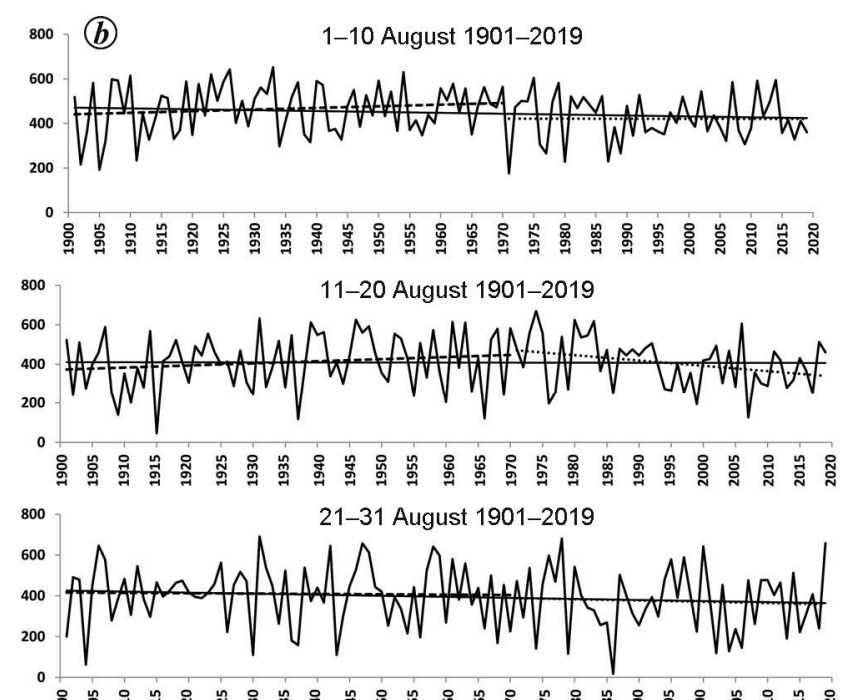

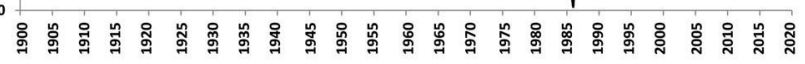

- Trend (1901-2019) ------Trend (1901-1970) _........ Trend (1971-2019)

Figure 6. Interannual variation of dekadal rainfall of MR events during (a) July and (b) August with trend lines-fitted for the total and two parts of the data period.

significantly positive trend (95\%) exhibiting a peak in 2019 with 127 HR events, while for the other dekads the trends were insignificantly positive.

This study analysed climatology, variability and trend of HR and MR events over Kerala for June-September using IMD's high spatial resolution $\left(0.25^{\circ} \times 0.25^{\circ}\right)$ daily gridded data for the period 1901-2019 and its two parts, viz. 1901-1970 and 1971-2019. Dekad-wise trend analysis for MR and HR events during July and August for the entire data period and its different parts was also carried out. The study examined grid-wise trend analysis of intensity of MR and HR events over Kerala, the spatial domain of which encloses 75 grids. Significant negative (99\%) long-term, linear trend was observed in the areaweighted rainfall season during the entire period; however, the trends were insignificantly negative during the two sub-periods. During the total data period, significant negative trends were observed in the frequency of MR as well as HR events (at 99.9\% and 95\% respectively). Among the sub-period trends, statistically insignificant positive (negative) trends were observed in the frequency of MR (HR) events during the first part. The trends during the second part were negative in both the events. The trend analysis of MR events was negative in all the dekads of July and August for the second part of data period. For all the dekads of August, the HR events showed a positive trend in which the first dekad (1-10) was $95 \%$ significant for the last 49 years, exhibiting a peak in 2019 with 127 HR events. Kerala has been experiencing exceptionally heavy rainfall spells of shorter duration (about 10 days) during July and August in recent years, causing damage to life and property. This can be attributed to the increasing trend observed in the HR events during all dekads of August for the last 49 years due to climate change. Grid-wise trend analysis of the frequency of MR events revealed that out of 75 grids, $13.3 \%(64 \%)$ showed significantly positive (negative) trends for the entire data period, $42.66 \%$ (37.35\%) showed significantly positive (negative) trends during the first part, and 64\% (21.33\%) showed significantly positive (negative) trend during the second part. For the HR events, $9.33 \%(25.3 \%)$ showed significantly positive 

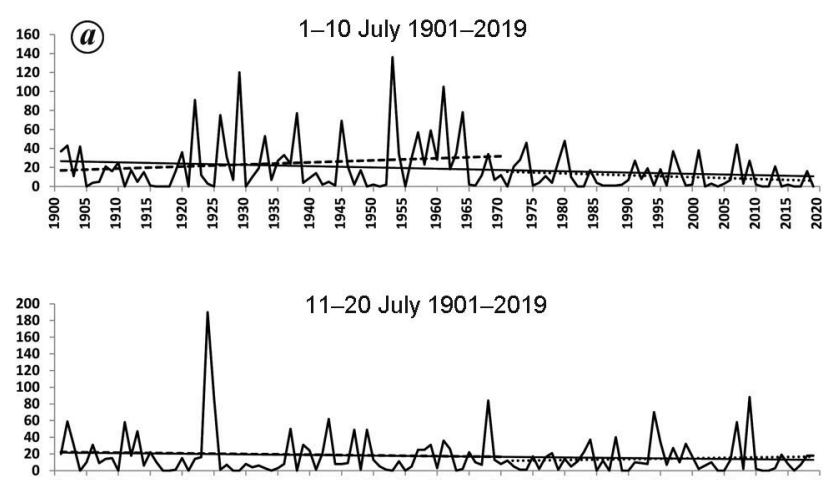

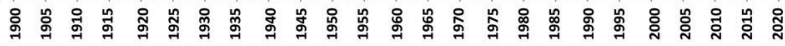

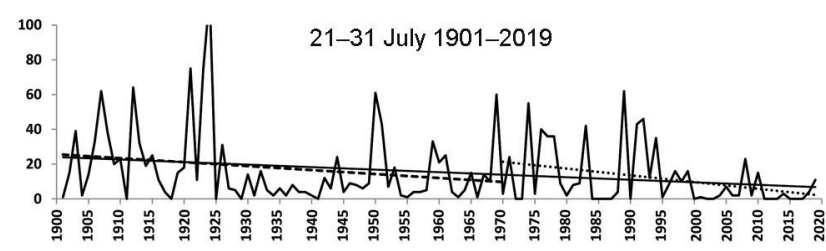

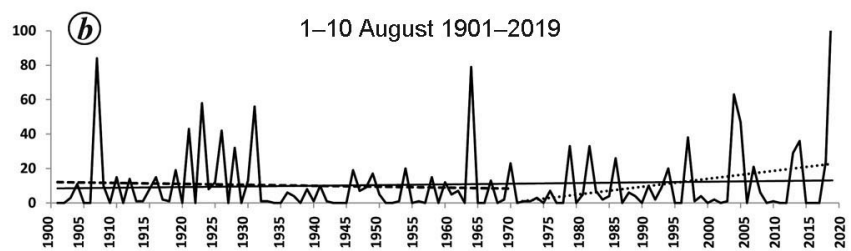

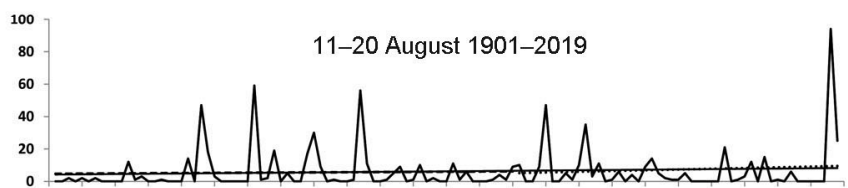

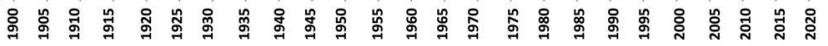

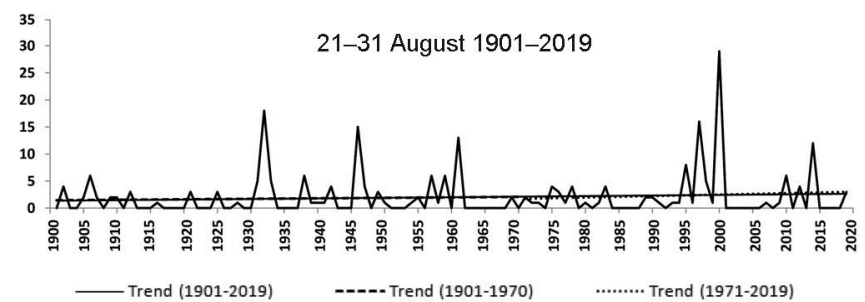

Figure 7. Interannual variation of dekadal rainfall of HR events during (a) July and (b) August with trend lines fitted for the total and two parts of the data period.

(negative) trends for the entire data period; $17.34 \%$ $(45.33 \%)$ showed significantly positive (negative) trends during the first part, and $21.33 \%(41.34 \%)$ showed significantly positive (negative) trends during the second part. The frequency of HR events over few grids of eastern Kerala showed significant increase in the second part of the data period, where the state recently experienced exceptionally heavy rainfall spells of shorter duration and landslides. Few grids thus exhibit possible disaster potential over Kerala. Further detailed analysis with regard to anthropogenic intervention on the orography and topography leading to disaster potential is required to enable mitigation of the effects of frequency and intensity of the MR and HR events on smaller spatial and temporal scales.

1. Singh, D., Tsiang, M., Rajaratnam, B. and Diffenbaugh, N. S., Observed changes in extreme wet and dry spells during the South Asian summer monsoon season. Nature Climate Change, 2014, 4(6), 456-461.

2. Ghosh, S., Das, D., Kao, S. C. and Ganguly, A. R., Lack of uniform trends but increasing spatial variability in observed Indian rainfall extremes. Nature Climate Change, 2012, 2(2), 86-91.

3. Goswami, B. N., Venugopal, V., Sengupta, D., Madhusoodanan, M. S. and Xavier, P. K., Increasing trend of extreme rain events over India in a warming environment. Science, 2006, 314(5804), 1442-1445.

4. Guhathakurta, P. and Rajeevan, M., Trends in the rainfall pattern over India. Int. J. Climatol., 2008, 28(11), 1453-1469.

5. Krishnakumar, K. N., Rao, G. P. and Gopakumar, C. S., Rainfall trends in twentieth century over Kerala, India. Atmos. Environ., 2009, 43(11), 1940-1944.
6. Nair, A., Joseph, K. A. and Nair, K. S., Spatio-temporal analysis of rainfall trends over a maritime state (Kerala) of India during the last 100 years. Atmos. Environ., 2014, 88, 123-132.

7. Nikhil Raj, P. P. and Azeez, P. A., Trend analysis of rainfall in Bharathapuzha River basin, Kerala, India. Int. J. Climatol., 2012, 32(4), 533-539.

8. Simon, A. and Mohankumar, K., Spatial variability and rainfall characteristics of Kerala. J. Earth System Sci., 2004, 113(2), 211221.

9. Soman, M. K., Krishna, K. K. and Singh, N., Decreasing trend in the rainfall of Kerala. Curr. Sci., 1988, 57, 7-12.

10. Pai, D. S., Sridhar, L., Rajeevan, M., Sreejith, O. P., Satbhai, N. S. and Mukhopadhyay, B., Development of a new high spatial resolution $(0.25 \times 0.25)$ long period $(1901-2010)$ daily gridded rainfall data set over India and its comparison with existing data sets over the region. Mausam, 2014, 65(1), 1-8.

11. Pai, D. S., Sridhar, L., Badwaik, M. R. and Rajeevan, M., Analysis of the daily rainfall events over India using a new long period $(1901-2010)$ high resolution $(0.25 \times 0.25)$ gridded rainfall data set. Climate Dyn., 2015, 45(3-4), 755-776.

ACKNOWLEDGEMENTS. We thank Dr M. Mohapatra (Director General of Meteorology, India Meteorological Department) and Dr M. Rajeevan (Secretary, Ministry of Earth Sciences, Government of India) for encouragement, guidance and support during various stages of this work.

Received 27 April 2020; revised accepted 5 June 2020

doi: $10.18520 / \mathrm{cs} / \mathrm{v} 119 / \mathrm{i} 3 / 545-550$ 